\title{
Development and Validation of Chemometric Assisted Methods and Stability Indicating RP-HPLC Method for Simultaneous Estimation of Rasagiline Mesylate and Pramipexole in Synthetic Mixture
}

\section{Riddhi Patel and Rajashree Mashru*}

Faculty of Pharmacy, GH Patel Building, Donor"s Plaza, The Maharaja Sayajirao University of Baroda, Vadodara, India

*Corresponding Author: Rajashree Mashru, Faculty of Pharmacy, GH Patel Building, Donor"s Plaza, The Maharaja Sayajirao University of Baroda, Vadodara, India.

Received: June 17, 2019; Published: July 31, 2019

DOI: $10.31080 /$ ASPS.2019.03.0359

\begin{abstract}
Rasagiline Mesylate is irreversible monoamine oxidase inhibitor used for treatment of Idiopathic Parkinson's disease. Pramipexole is a non - ergotine dopamine agonist and used for treatment of early stage Parkinson's disease. In combination of both drugs shows synergistic effect. The Chemometric assisted UV method and Stability indicating RP-HPLC method has been developed for the simultaneous estimation of Rasagiline Mesylate and Pramipexole in synthetic mixture. The mobile phase consisted of $10 \mathrm{mM}$ Acetate Buffer: Acetonitrile $(75: 25 \mathrm{v} / \mathrm{v})$ at $0.8 \mathrm{ml} / \mathrm{min}$ flow rate with UV detection at $265 \mathrm{~nm}$. Method found to be linear for both drugs at an analytical range of 15- $90 \mu \mathrm{g} / \mathrm{ml}$ and 6- $36 \mu \mathrm{g} / \mathrm{ml}$ for Rasagiline Mesylate and Pramipexole respectively. Retention time for Rasagiline Mesylate and Pramipexole was $3.3 \mathrm{~min}$ and $6.1 \mathrm{~min}$ respectively. Force degradation studies were performed by exposition of drug to hydrolytic (acidic and basic), Photolytic and heat stress condition.

Keywords: Rasagiline Mesylate; Pramipexole; Stability Indicating; Chemometric; RP-HPLC
\end{abstract}

\section{Introduction}

Chemometric methods are one type of multivariate analysis i.e. considering more than one variable at a time. When applied to UV spectrophotometry, many wavelengths are taken as variable and absorbance at each wavelength is considered. Least square approach involves mathematical modelling by which the square of residual (difference between actual and predicted concentration) is minimized to lowest level. Four different Chemometric methods are used which are
1. Classical Least Squares
2. Inverse Least Squares
3. Principal Component Regression
4. Partial Least Squares or Projection to Latent Structures

These methods first calibrate the mathematical model by using absorbance data of calibration standards with known concentration and then predict the concentration of un-known samples from their absorbance data. If there are m number of calibration standards and $\mathrm{l}$ chemical components (drugs) and $\mathrm{n}$ is the number of wavelengths considered, all methods involve presentation of absorbance data as a matrix with m rows and $\mathrm{n}$ columns, concentration data as a matrix with $\mathrm{m}$ row and $\mathrm{l}$ columns.

According to ICH guidelines stability means "An ability of pharmaceutical product to retain its physical, chemical, microbiological properties within specifications throughout its shelf life" Elaborate definitions of stability-indicating methodology are provided in the United States-Food and Drug Administration (US-FDA) stability guideline of 1987 and the draft guideline of 1998.

Stability-indicating methods according to 1987 guideline were defined as the „Quantitative analytical methods that are based on the characteristic structural, chemical or biological properties of each active ingredient of a drug product and that will distinguish each active ingredient from its degradation products so that the 
active ingredient content can be accurately measured." This definition in the draft guideline of 1998 reads as: „Validated quantitative analytical methods that can detect the changes with time in the chemical, physical, or microbiological properties of the drug substance and drug product, and that are specific so that the contents of active ingredient, degradation products, and other components of interest can be accurately measured without interference".

Ideal characteristics of SIA method

- It should be capable of separating major API from any degradation product under defined storage condition.

- It should be sensitive to detect and quantify one or more degradation products or impurities or related substances.

\section{Modes of degradation}

Chemical degradation (solvolysis, oxidation, etc) is common. The cause of chemical deterioration include incompatibility, oxidation, reduction, hydrolysis, racemization etc. oxidation is prime cause of product instability. Drugs containing an ester or amide linkage are prone to hydrolysis.

Photolytic degradation can be an important limiting factor in the stability of pharmaceuticals. A drug can be affected chemically by the radiation of particular wavelength only if it absorbs radiation at that wavelength and the energy exceeds a threshold. UV radiation which has a high energy level is the cause of much degradation. Physical degradation can be caused by range of factors (e.g., impact, vibration, and abrasion and temperature fluctuations).

Potential adverse effects of instability in pharmaceutical products

- Loss of Active Pharmaceutical Ingredient (API)

- Increase in concentration of API

- Alteration in bioavailability

- Loss of content uniformity

- Loss of pharmaceutical elegance and patient acceptability

- Formation of toxic degradation products

- Loss of package integrity
Rasagiline Mesylate is chemically known as (R)-N-(prop-2-ynyl)2,3-dihydro-1H-inden-1-amine, it is an Irreversible Monoamine oxidase inhibitor used for the treatment of idiopathic Parkinson's disease. Molecular formula of Rasagiline Mesylate is $\mathrm{C}_{12} \mathrm{H}_{13} \mathrm{~N}$ and molecular mass is $171.238 \mathrm{~g} / \mathrm{mol}$. It is white amorphous powder. It is soluble in water and methanol, insoluble in ACN.

Pramipexole is chemically known as (S)-N6-propyl-4,5,6,7tetrahydro-1,3-benzothiazole-2,6-diamine, it is a non-ergoline dopamine agonist indicated for treating early stage Parkinson's disease (PD) and restless legs syndrome (RLS). Molecular formula of Pramipexole is $\mathrm{C}_{10} \mathrm{H}_{17} \mathrm{~N}_{3} \mathrm{~S}$ and molecular mass is $211.324 \mathrm{~g} / \mathrm{mol}$. It is white amorphous powder. It is soluble in water and methanol, insoluble in ACN.

\section{Why this combination? [1]}

- Monoamine oxidase-B inhibitors or dopamine agonists are approved treatments for early PD patients are associated with efficacy or safety limitations.

- Low doses of the dopamine agonists Pramipexole, and the monoamine oxidase-B inhibitor Rasagiline that have complementary mechanisms of action. Preclinical studies demonstrate that the combination provides synergistic effects, which are further enhanced if both agents are given in slow release.

- The synergy between the combination components implies that lower doses maybe used without compromising the therapeutic effect, while maintaining manageable safety profile, due to the decreased drug amounts.

- $\quad$ Phase III clinical trial for this combination implies that it may provide significant therapeutic effects comparable to those published for higher doses of the individual components, with favourable safety profile.

Several UV methods reported for Rasagiline Mesylate. HPLC method reported for estimation of Rasagiline Mesylate in bulk and tablet dosage form [2-5]. 
Several UV methods reported for estimation of Pramipexole. HPLC method reported for estimation of Pramipexole [6-9]. There is no single method is reported for simultaneous estimation of Rasagiline Mesylate and Pramipexole in synthetic Mixture.

\section{Materials and Methods}

Instrument

Shimadzu UV-1700 double beam spectrophotometer connected to a computer loaded with Shimadzu UV Probe 2.10 software was used for all the spectrophotometric measurements. The absorbance spectra of the reference and test solutions were carried out in $1 \mathrm{~cm}$ quartz cells over the range of 200-400 nm. The samples were weighed on electronic analytical balance $(A \times 120$, Shimadzu). Statistical Analysis of Data was accomplished using Microsoft Excel 2013.

\section{Material and Reagents}

Rasagiline mesylate and Pramipexole API

\section{Selection of a solvent}

Both the Drugs were soluble in Methanol. So, Methanol was selected as a solvent for estimation of both the Drugs.

Preparation of standard stock and working standard solution

Preparation of standard stock solution of Rasagiline mesylate (1000 $\mu \mathrm{g} \backslash \mathrm{ml})$ : Weighed accurately $10 \mathrm{mg}$ of Rasagiline mesylate and was transferred into $10 \mathrm{ml}$ volumetric flask, volume was made up to the mark with Methanol.

Preparation of working standard solution of Rasagiline mesylate $(100 \mu \mathrm{g} \backslash \mathrm{ml})$ : Aliquot of $1 \mathrm{ml}$ was withdrawn from the stock solution and transferred into $10 \mathrm{ml}$ volumetric flask and diluted with Methanol to obtain $100 \mu \mathrm{g} / \mathrm{ml}$.

Preparation of standard stock solution of Pramipexole (1000 $\mu \mathrm{g} / \mathrm{ml}$ ): Weighed accurately $10 \mathrm{mg}$ of Pramipexole and was transferred into $10 \mathrm{ml}$ volumetric flask, diluted to half and sonicated and made up to the mark with Methanol. $(1000 \mu \mathrm{g} / \mathrm{ml})$ Preparation of working standard solution of Pramipexole $(100 \mu \mathrm{g} \backslash \mathrm{ml})$ : Aliquot of $1 \mathrm{ml}$ was withdrawn from the stock solution and transferred into $10 \mathrm{ml}$ volumetric flask and diluted with Methanol to obtain $100 \mu \mathrm{g} /$ $\mathrm{ml}$.

\section{Method development [10]}

\section{Classical first derivative zero crossing method}

Derivative spectra can be used to enhance differences among spectra, to resolve overlapping bands in qualitative analysis and most importantly, to reduce the effects of interference from scattering, matrix or other absorbing compounds in quantitative analysis.
Procedure for selection of wavelength

$1.5 \mathrm{ml}$ working standard solution of Rasagiline mesylate (100 $\mu \mathrm{g} / \mathrm{ml})$ and $0.6 \mathrm{ml}$ working standard solution of Pramipexole (100 $\mu \mathrm{g} / \mathrm{ml}$ ) was transferred into different $10 \mathrm{ml}$ volumetric flask and dilute up to mark with Methanol to get $15 \mu \mathrm{g} / \mathrm{ml}$ of Rasagiline mesylate and $6 \mu \mathrm{g} / \mathrm{ml}$ of Pramipexole. Each solution was scanned in the range of $200-400 \mathrm{~nm}$. Zero Order spectra were converted into First Order spectra. Rasagiline mesylate shows ZCP (Zero Crossing Point) at $286 \mathrm{~nm}$ and Pramipexole show ZCP at $228 \mathrm{~nm}$. Hence, these wavelengths 228 and 286 were selected as analytical wavelengths for Rasagiline mesylate and Pramipexole respectively. $1^{\text {st }}$ derivative spectra of Rasagiline Mesylate is shown in Figure 1, Pramipexole in Figure 2 and overlay spectra of both drugs shown in Figure 3.

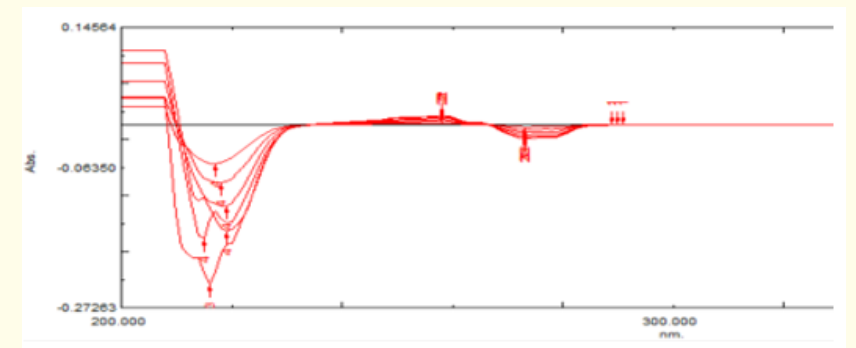

Figure 1: $1^{\text {st }}$ derivative spectra of Rasagiline mesylate.

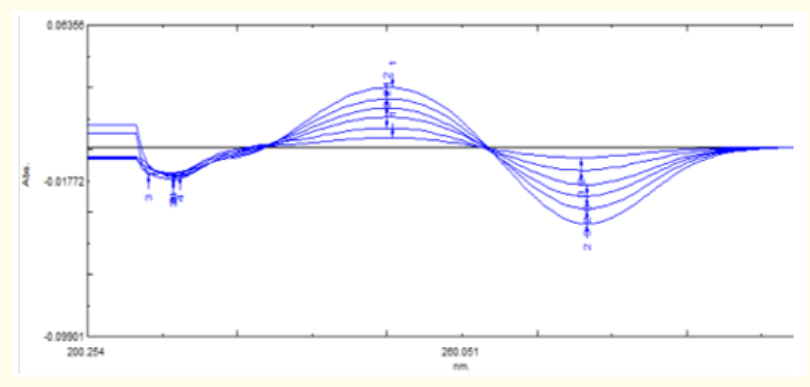

Figure 2: $1^{\text {st }}$ derivative spectra of Pramipexole.

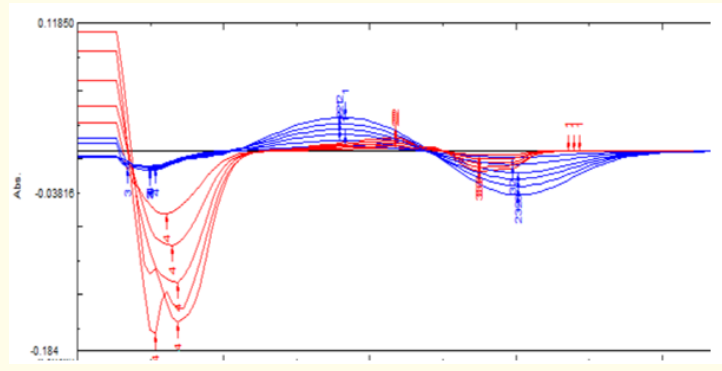

Figure 3: Overlain Spectra of RASA and PRAMI. 


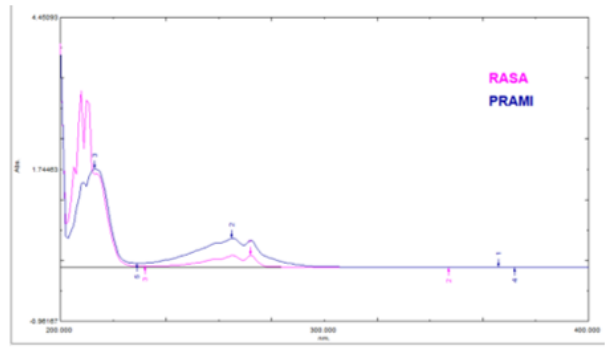

Figure 4: Overlain spectra of Rasagiline Mesylate and Pramipexole.

\section{Method validation [11]}

Developed spectrophotometric methods for the simultaneous estimation of RASA and PRAMI were validated according to ICH Q2 (R1) guidelines and data complying with the standards were obtained. The proposed technique has been extensively validated in terms of linearity, accuracy and precision, limit of detection and limit of quantification.

\section{Linearity and Sensitivity}

The linearity of method was evaluated thrice by analyzing six concentration of each drug. Linear regression equation was obtained over the concentration range $(y=m x+c)$. Limit of Detection (LOD) and Limit of Quantification (LOQ) were calculated from standard deviation of response and slope of calibration curve. Table reveal the Summary of Validation parameters of RASA and PRAM (Table 3).

\section{Precision}

Intraday and Interday precision was measured in terms of $\%$ RSD. The experiment was repeated 3 times a day for intraday and for 3 different days for inter-day precision. The average \% RSD was found to be less than $2.0 \%$ for both the methods (Table 4 ).

\section{Accuracy}

To check the Accuracy of different methods, Recovery studies were carried out from pre-analyzed sample at three deferent level of standard addition $80 \%, 100 \%$ and $120 \%$. Results of Recovery studies are shown in Table 5. For each of the method explained above, \%Recovery was the average of three determinations at each standard addition level. \%Recovery for different methods was found to be between $98 \%-102 \%$ which prove that all the methods were accurate (Table 5).
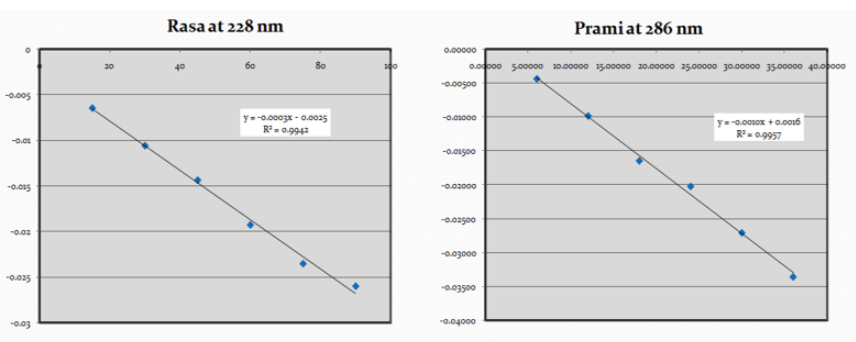

Figure 5: Calibration curve for - First derivative ZCP method.

\section{Applicability of Proposed Uv Method}

Result of Simultaneous estimation of RASA and PRAMI in synthetic mixture given in Table 6.

\section{Chemometric Methods [12-15]}

Chemometric methods are one kind of multivariate analysis in which multiple measurements are made on a sample of interest. So, more than one variable or response are measured for each sample.

The Chemometric quantitative analytical techniques have many applications and advantages such as

- Allow the resolution of the complex spectra of mixtures of analytes.

- The mixtures can be analyzed without any separation procedures for drug determination.

- The techniques are very easy to apply, very sensitive, useful and yet very inexpensive as compared to other analytical techniques for simultaneous determination of compounds in multicomponent mixtures.

- $\quad$ Allow the interpretation of multivariate data and is vital to the success of the simultaneous determination of the organic components.

Multivariate methods include two type of methods

- $\quad$ Factor-based methods:

- $\quad$ Principal Component Regression (PCR)

- $\quad$ Partial Least Squares (PLS)

Preparation of binary mixtures (RASA + PRAMI) for calibration set and validation set

- $\quad$ Appropriate and accurate volume aliquots of the stock solutions were taken according to following Binary mixture scheme and volume made up to $10 \mathrm{ml}$ with methanol. 
- The absorbance data matrix was obtained by measuring the absorbance at each wavelength points (250 to $275 \mathrm{~nm}$ ) in spectral region between 250 to $275 \mathrm{~nm}$.

- $\quad 36$ sets are taken for Calibration set and for validation set.

\section{Calibration Set}

A set of 26 mixtures was prepared in methanol, applying a multilevel multifactor design in which two levels of concentrations of RASA and PRAMI within the stated range were introduced as shown in Table 1.

\begin{tabular}{|c|c|}
\hline RASA (ppm) & PRAMI (ppm) \\
\hline 75 & 30 \\
\hline 15 & 30 \\
\hline 90 & 18 \\
\hline 45 & 18 \\
\hline 90 & 30 \\
\hline 90 & 12 \\
\hline 90 & 36 \\
\hline 30 & 18 \\
\hline 60 & 12 \\
\hline 75 & 6 \\
\hline 30 & 12 \\
\hline 15 & 24 \\
\hline 45 & 30 \\
\hline 30 & 30 \\
\hline 60 & 30 \\
\hline 15 & 12 \\
\hline 15 & 6 \\
\hline 75 & 24 \\
\hline 90 & 24 \\
\hline 45 & 36 \\
\hline 60 & 36 \\
\hline 45 & 6 \\
\hline 30 & 24 \\
\hline 60 & 24 \\
\hline 60 & 18 \\
\hline 75 & 36 \\
\hline
\end{tabular}

Table 1: Calibration Set.

\section{Validation set}

A set of 10 mixtures was prepared in water, applying a multilevel multifactor design in which two levels of concentrations of RASA and PRAMI within the stated range were introduced as shown in Table 2.

\begin{tabular}{|l|c|}
\hline RASA & PRAMI \\
\hline 90 & 6 \\
\hline 75 & 12 \\
\hline 30 & 36 \\
\hline 15 & 36 \\
\hline 45 & 12 \\
\hline 30 & 6 \\
\hline 75 & 18 \\
\hline 45 & 24 \\
\hline 15 & 18 \\
\hline 60 & 6 \\
\hline
\end{tabular}

Table 2: Validation Set.

\section{Producing absorbance matrix A}

Absorbance matrix A was produced by measuring absorbance at 26 wavelengths in the spectrum region between the $250 \mathrm{~nm}$ to $275 \mathrm{~nm}$. This region was selected because it contained most relevant information about both the drugs. The spectra of prepared binary mixture standards were recorded in the range of 250 to 275 $\mathrm{nm}$. Absorbance values in this wavelength region were recorded figure 6.

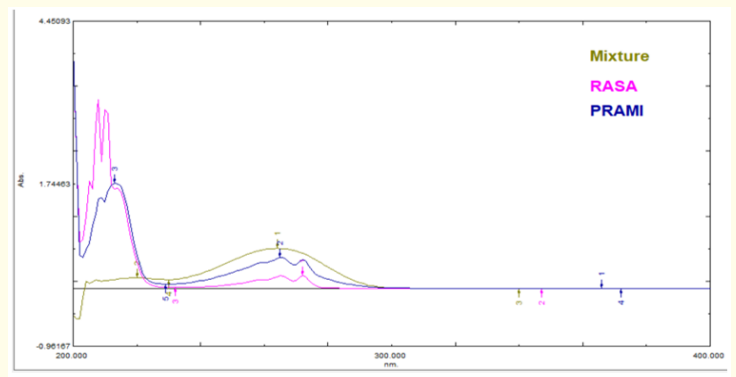

Figure 6: Overlain spectra of PRAMI and RASA and mixture. 


\section{Principal component regression}

PCR is the method which works on the principal of reducing the dimensionality of the original data. Absorbance matrix and concentration matrix as shown above were generated and data was fed to software. The absorbance matrix (X) used for calibration contains total 26 variables i.e. wavelengths at which absorbance values are measured. PCR will compute a few PCs and will perform regression of these PCs with concentration (Y). Validation was set as full cross validation. The data of absorbance values at 26 wavelengths were used as X space (predictors) and the data containing concentration of RASA and PRAMI in 26 calibration standards were used as $Y$ space (responses) (Figure 7and 8).

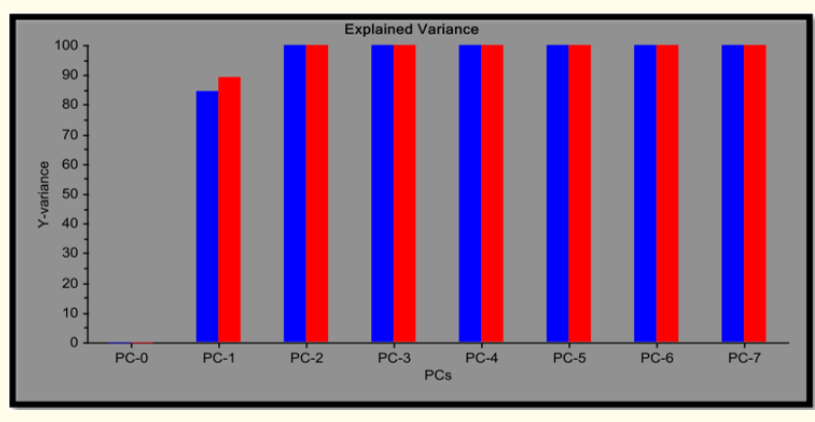

Figure 7: Total explained Y variance.

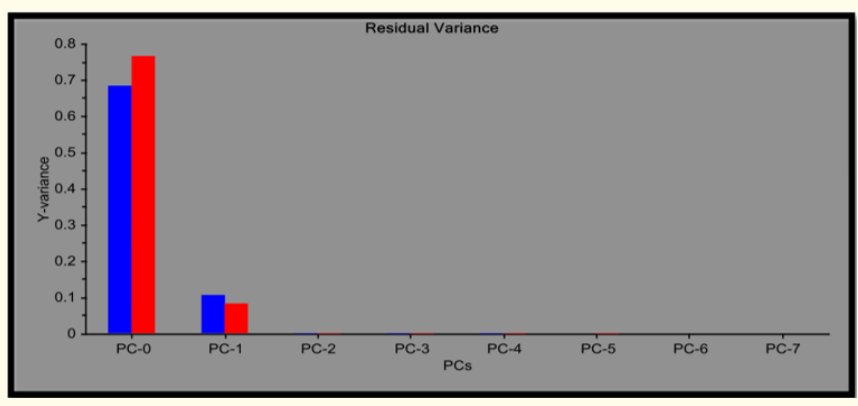

Figure 8: Total residual Y variance.

Determining optimum number of principal components for PCR

Three major parameters are considered for determination of number of PCs to be taken into account.
Effect of number of PCs on Explained Y-variance (PCR) - should be high (Near To 100) Effect of number of PCs on Residual variance (PCR) - should be low (Near to Zero).

Determining optimum number of principal components for PCR

Three major parameters are considered for determination of number of PCs to be taken into account.

Effect of number of PCs on Explained Y-variance (PCR) - should be high (Near To 100) Effect of number of PCs on Residual variance (PCR) - should be low (Near to Zero).

\section{Root mean square of prediction values for validation}

(Concentrations are Y space - the responses; and absorbance values at different wavelengths are considered as $X$ space - the predictors. Mixtures prepared as calibration standards may be referred to as samples.)

The model should have as low residual variance as possible. This means that the model should explain most of the variance in the data i.e. explained variance should approach 100\%. For this, number of PCs should be optimized. Normally, first 2-3 PCs will explain nearly (not exactly) $100 \%$ of variance in data. Moreover, the model should have as low RMSEP values as possible.

- $\quad$ The software can validate the model by full cross validation method, where one sample from the calibration set is left out each time and model is calibrated using remaining samples. Then the prediction is made for left out sample and its residual is calculated. The same process is repeated until each sample is left out once. So, there were total 17 segments for validation, because there were 17 calibration standards or samples. Finally, one can view the plot of residual variance or explained variance (for calibration and validation both) or RMSEP vs. number of PCs. This can help in determining the optimum number of PCs.

- $\quad$ Once the model is calibrated with optimum number of PCs, the model can predict the unknown concentration from its absorbance data.

- Maximum number of PCs was fixed to 7 and the parameters are discussed below. 


\section{Partial least squares or projection to latent structures}

Theoretical Aspects of this method are explained in Chapter1, Section 1.5. PLS computes factors for $\mathrm{X}$ and $\mathrm{Y}$ both and then correlates them. It models both the X-and Y-matrices simultaneously to find the latent variables in $\mathrm{X}$ that will best predict the latent variables in Y. Full cross validation method is used for determining the optimum number of factors (Figure 9 and 10).

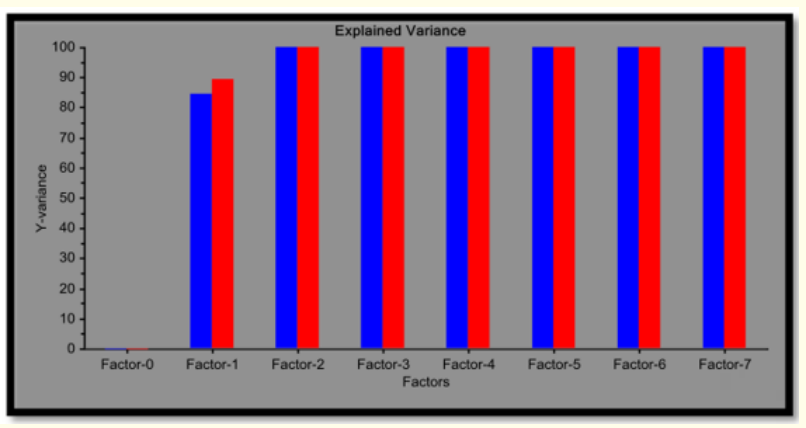

Figure 9: Total explained Y variance.

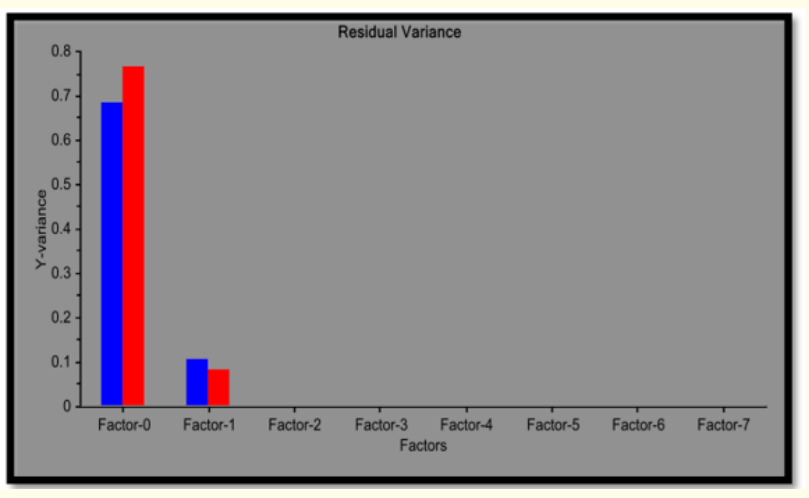

Figure 10: Total residual Y variance.

The algorithm used for PLS was NIPALS i.e. nonlinear iterative partial least squares.

Determining Optimum Number of Principal Factors for PLS

The number of factors to be taken into account was determined by full cross validation method and following parameters were considered:

1. Total explained $Y$ variance

2. Total residual $Y$ variance

3. RMSEP values for validation

\section{Validation of PCR and PLS models}

The validation set prepared as described in previous was subjected to analysis by developed models of all the four methods. Though the PCR and PLS models are validated using full cross validation, these methods are also applied to validation set. The validation parameters are discussed below.

\section{Predicted vs. actual concentration plot}

Predicted vs. Actual concentration plots for RASA and PRAMI for all four different methods are shown below in Figure 11 and Figure 12 respectively. Predicted concentration of validation samples were plotted against the actual concentration values. This tool is used to determine whether the model accounts for concentration variation in the validation set or not. Plots were expected to fall on straight line with slope of 1 and 0 intercept. It was noticed RASA and PRAMI in all samples lay on straight line and the equations of these lines are shown on the graph. This indicates that the prediction ability of the validation set is very much better in terms of recovery (figure 11-14).

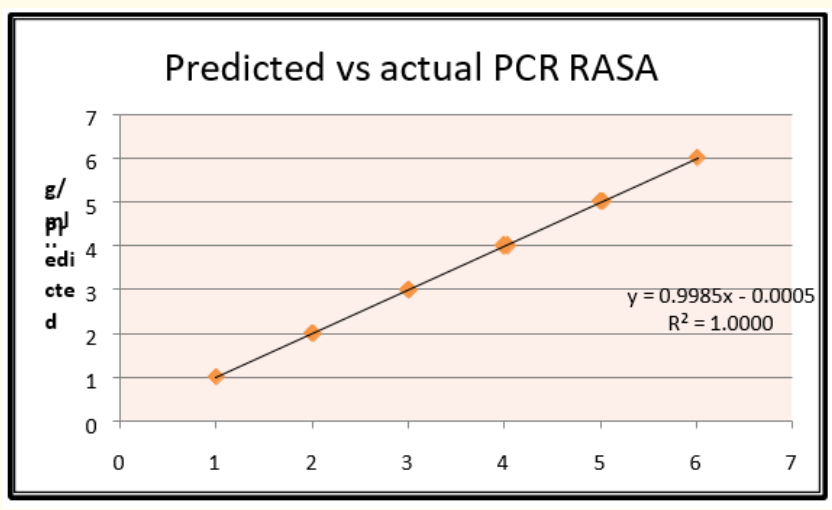

Figure 11: Predicted vs Actual Conc of RASA.

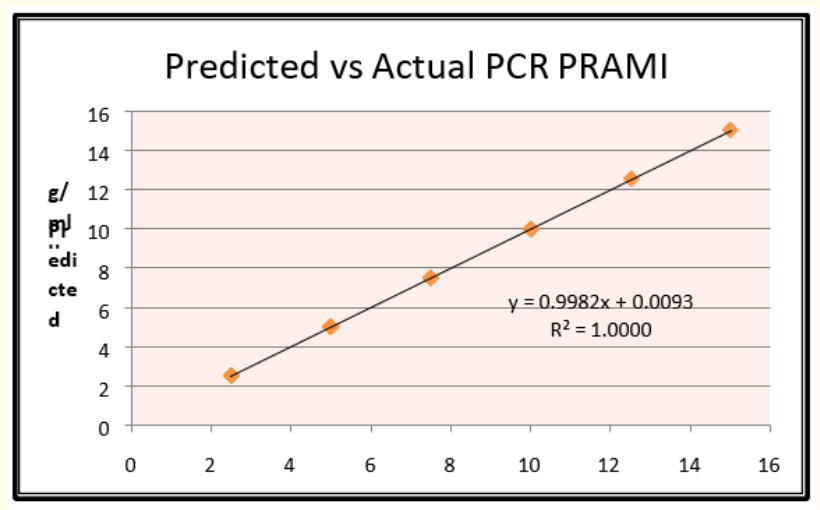

Figure 12: Predicted vs Actual Conc of PRAMI. 


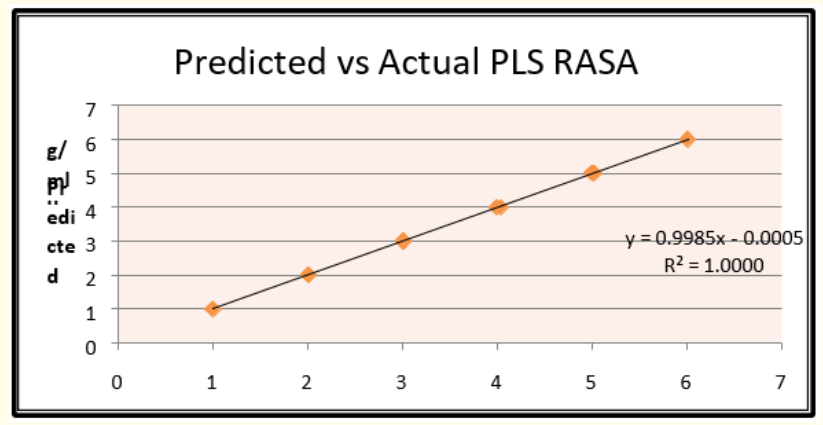

Figure 13: Predicted vs Actual Conc of RASA for PLS.

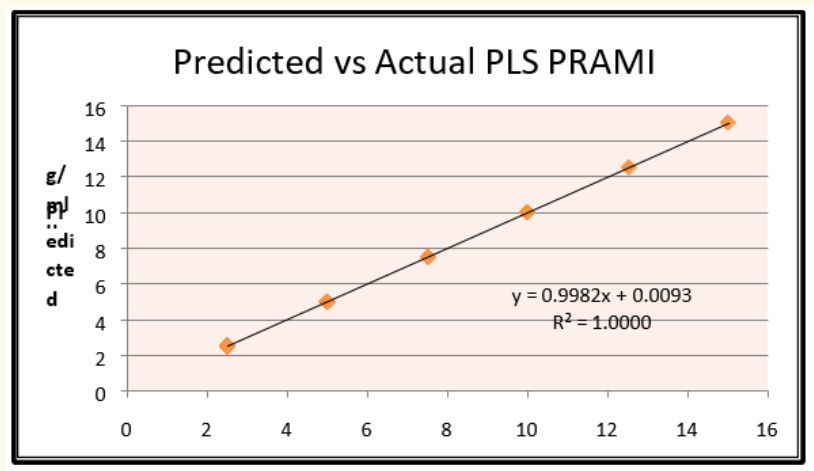

Figure 14: Predicted vs Actual Conc of PRAMI for PLS.

Residual vs. Actual concentration plot the differences between the actual and predicted concentration (Residuals) were plotted against actual concentration of validation samples. This tool is used to determine whether the model accounts for the concentration variation in the validation set and it also provides information about how well the method will predict the future sample. For the validation set it can be found that the residual values more close to zero and more randomly distributed (Figure 15-18).

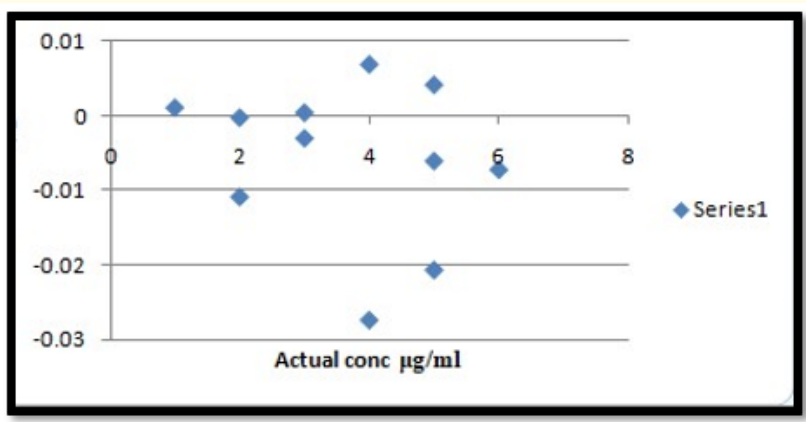

Figure 15: Residual vs Actual Conc of RASA for PCR.

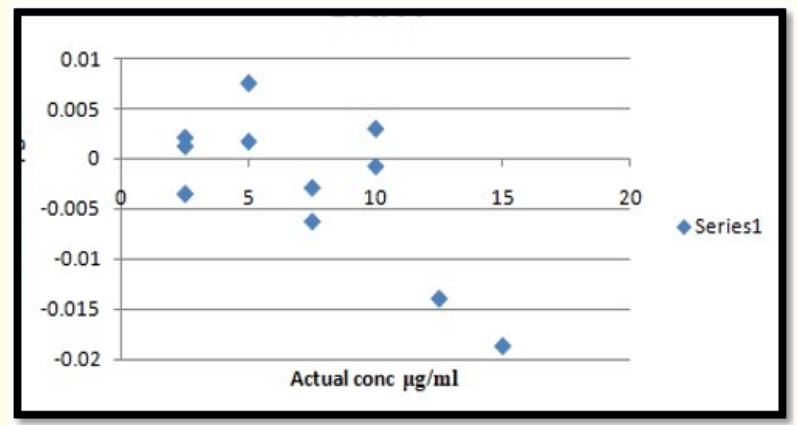

Figure 16: Residual vs Actual Conc of PRAMI for PCR.

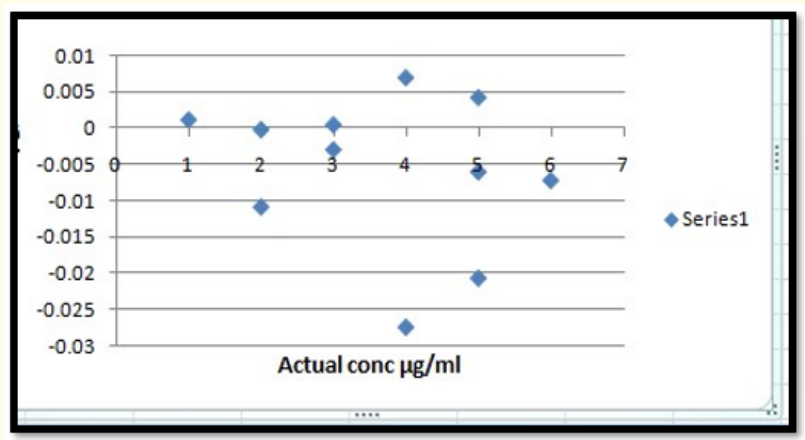

Figure 17: Residual vs Actual Conc of RASA for PLS.

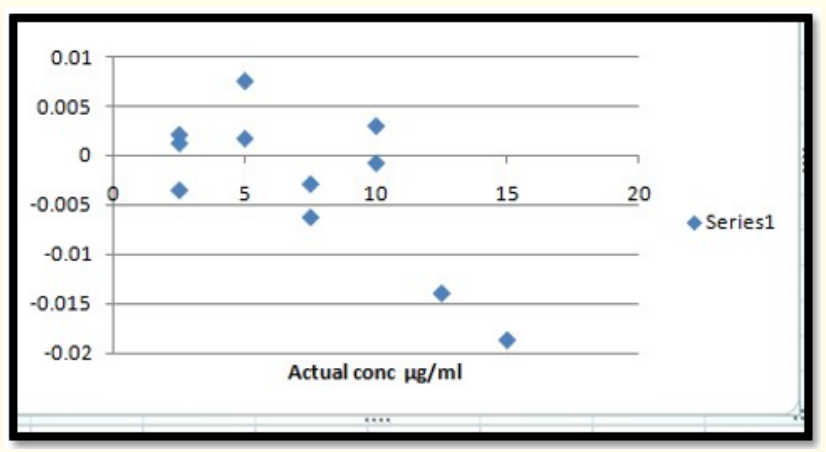

Figure 18: Residual vs Actual Conc of PRAMI for PLS.

\section{RMSEP value}

Root Mean Square Error of Prediction (RMSEP)

The predictive ability of the model can be defined as RMSEP. RMSEP summarizes both Precision and Accuracy. It is used for examining the errors in the predicted concentration. It is calculated from following formula.

RMSEP $=\sqrt{\frac{\sum_{i=1}^{n}\left(\hat{y}_{i}-y_{i}\right)}{n}}$ 
Where, $\mathrm{N}$ is the number of samples used for validation i.e. 8. The results of future predictions can then be presented as "predicted values $\pm 2 \bullet$ RMSEP" (Table 7 ).

Applicability of The Developed Chemometric Methods

All four methods were successfully applied for the estimation of PRAMI and RASA in synthetic mixture (Table 8).

Development and Validation for Simultaneous Estimation of Rasagiline Mesylate and Pramipexole in Bulk and Synthetic Mixture by Isocratic Reverse Phase - High Performance Liquid Chromatographic (Rp-Hplc) Method.

\section{HPLC instrumentation}

Chromatography was performed on Shimadzu (Shimadzu Corporation, Kyoto, Japan) chromatographic system equipped with Shimadzu LC-20AT pump and Shimadzu SPD-20AV absorbance detector. Samples were injected through a Rheodyne 7725 injector valve with fixed loop at $20 \mu \mathrm{L}$. Data acquisition and integration was performed using LC Solutions software. HyperChrom ODS -BP (250 $\mathrm{mm} \times 4.6 \mathrm{~mm}, 5 \mu \mathrm{m}$ ) was used for separation.

Reagents and chemicals

Rasagiline Mesylate and Pramipexole API.

Acetonitrile (HPLC grade, Spectrochem Pvt ltd,Mumbai). Double distilled water (Purified HPLC grade water was obtained by filtering double distilled water through nylon filter paper $0.2 \mu \mathrm{m}$ pore size and $47 \mathrm{~mm}$ diameter. Ammonium acetate buffer HPLC grade.

Preparation of standard stock and working standard solutions

- Preparation of standard stock solution of Rasagiline Mesylate (1000 $\boldsymbol{\mu g} \backslash \mathbf{m l})$ : Weighed accurately 10 -mg of Rasagiline Mesylate and was transferred into $10 \mathrm{ml}$ volumetric flask, volume was made up to the mark with Methanol. $(1000 \mu \mathrm{g} / \mathrm{ml})$

- Preparation of working standard solution of Rasagiline Mesylate (100 $\boldsymbol{\mu g} \backslash \mathbf{m l})$ : Aliquot of $5 \mathrm{ml}$ was withdrawn from the stock solution and transferred into $50 \mathrm{ml}$ volumetric flask and diluted with Methanol to obtain 100 $\mu \mathrm{g} / \mathrm{ml}$.

- Serial dilutions of Rasagiline Mesylate (15 - $90 \mu \mathrm{gg} \backslash$ ml): Withdraw $1.5,3,4.5,6,7.5$, and $9.0 \mathrm{ml}$ from the working standard solution and each transferred into 10 ml volumetric flasks and diluted with Methanol to obtain $15,30,45,60,75,90 \mu \mathrm{g} / \mathrm{ml}$ respectively.
- Preparation of standard stock solution of Pramipexole (1000 $\mu \mathrm{g} \backslash \mathrm{ml}$ ): Accurately weighed 10mg of Pramipexole and was transferred into $10 \mathrm{ml}$ volumetric flask, diluted to half and sonicated and made up to the mark with Methanol. $(1000 \mu \mathrm{g} /$ $\mathrm{ml}$ )

- Preparation of working standard solution of Pramipexole (100 $\mu \mathrm{g} \backslash \mathbf{m l})$ : Aliquot of $25 \mathrm{ml}$ was withdrawn from the stock solution and transferred into $25 \mathrm{ml}$ volumetric flask and diluted with Methanol to obtain $100 \mu \mathrm{g} / \mathrm{ml}$.

- Serial dilutions of Pramipexole $(6,12,18,24,30,36 \mu \mathrm{g} \backslash$ $\mathbf{m l}$ ): Withdraw $0.6,1.2,1.8,2.4,3.0$ and $3.6 \mathrm{ml}$ from the working standard solution and each transferred into $10 \mathrm{ml}$ volumetric flasks and diluted with Methanol to obtain 6, 12, 18, 24, 30 and $36 \mu \mathrm{g} / \mathrm{ml}$ respectively.

Method development

Selection of analytical wavelength

Standard solutions of RASA and PRAMI were scanned between 200-400 nm in UV-visible spectrophotometer and showed good sensitivity at $265 \mathrm{~nm}$ as shown in Figure 19 which was selected as the analytical wavelength.

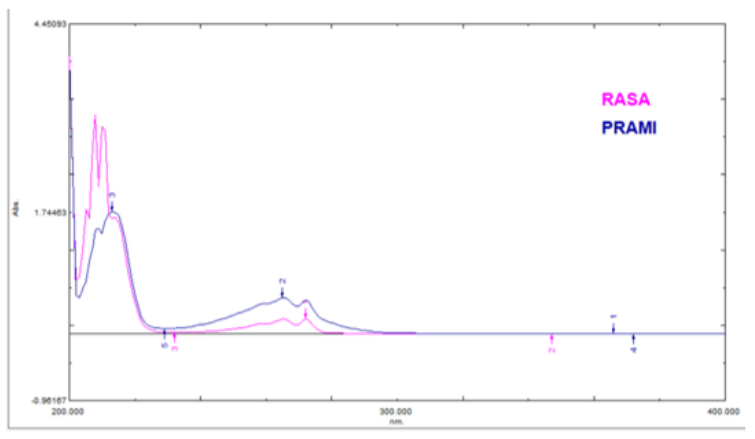

Figure 19: Overlain spectra of PRAMI and RASA.

\section{Method validation}

Developed RP-HPLC method was validated according to ICH Q2 (R1) guidelines and data complying with the standards were obtained.

\section{Linearity}

The calibration curve was constructed by plotting concentrations of RASA and PRAMI versus their respective peak areas, and the regression equations were calculated. The linearity of the method was investigated by using concentrations in the range 15- 
Development and Validation of Chemometric Assisted Methods and Stability Indicating RP-HPLC Method for Simultaneous Estimation of Rasagiline Mesylate and Pramipexole in Synthetic Mixture

$90 \mu \mathrm{g} / \mathrm{ml}$ for RASA and 6- $36 \mu \mathrm{g} / \mathrm{ml}$ for PRAMI. Retention times for RASA and PRAMI were found to be $3.325 \mathrm{~min}$ and $6.148 \mathrm{~min}$ respectively. Overlay spectra of combination shown in Figure 20.

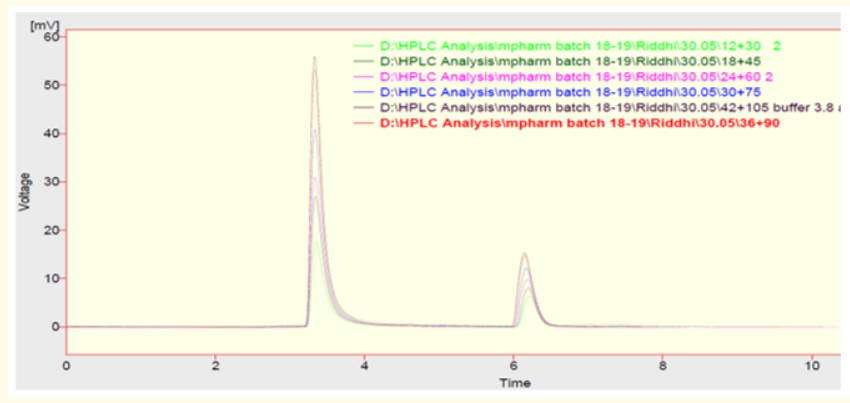

Figure 20: Calibration curve overlay.

\section{Recovery studies}

Accuracy of the method was studied using standard addition method at three different levels $(80,100$, and $120 \%)$ by recovery experiments. Known amounts of standard solutions containing RASA and PRAMI were added to prequantified sample solutions to reach $80 \%, 100 \%$ and $120 \%$ levels. Percentage Recovery was the mean of three determinations at each standard addition level (Table 9).

\section{Precision}

To demonstrate agreement among results, a series of measurements were done. Three replicate injections of specific standard at various time intervals on the same day were injected into system for intraday precision and were repeated on three different days for interday precision. The \% RSD (Relative Standard Deviation) of the results was calculated (Table 10).

\section{Sensitivity}

The limit of detection (LOD) and limit of quantification (LOQ) which determines the sensitivity of method are calculated by equation 1 and 2

$$
\begin{aligned}
& \mathrm{LOD}=3.3 \sigma / \mathrm{S} \ldots \ldots \ldots . . .(1) \\
& \mathrm{LOQ}=10 \sigma / \mathrm{S} \ldots \ldots \ldots \ldots . . . .(2)
\end{aligned}
$$

Where " $\sigma$ " is the standard deviation of intercepts and " $S$ " is the slope of response (Table 11).

\section{System suitability parameters}

System suitability testing was carried out on freshly prepared standard solution $(n=6)$ of RASA and PRAMI. System suitability parameters obtained with $20 \mu$ injection volumes are summarized in Table 12.

Summary of validation result for developed method is given in Table 13.

Applicability of proposed method

Assay

Tablets were crushed to powder and were dissolved in $10 \mathrm{ml}$ of methanol. Solution was centrifuged and filtered through $0.2 \mathrm{um}$ syringe filter. $1 \mathrm{ml}$ aliquot was drawn and volume was made up to $10 \mathrm{ml}$ with mobile phase and sample was injected into HPLC (Table 14).

\section{Forced degradation study}

Stress conditions under which a drug is forced degraded are fairly constant, the time of exposure and extent of degradation may vary from day to day. The general guideline for developing a stability-indicating assay procedure is to expose the drug to stress conditions to produce sufficient degradation. The stability-indicating assay method should be able to estimate the remaining drug without the interference of known or unknown degraded product.

For development of stability-indicating assay method, stress degradation is important. By degrading the drug under stress condition, we can understand the path of degradation, degradation kinetics, which products are going to be formed due to degradation.

To ascertain a method's stability-indicating capability, it is necessary to perform a forced degradation study. Generally, a forced degradation study is performed prior to commercial stability testing by exposing the drug to variety of extreme condition, such as $\mathrm{pH}$, photolysis, oxidation and temperature; over a very short time period.

Drug is exposed to a range of $\mathrm{pH}$ levels to ascertain the drug's susceptibility to hydrolysis. Photolysis of drug demonstrates whether exposure to light result in unacceptable changes. Oxidation and elevated temperatures potentially generate a variety of impurities that may differ from that of the photolysis or $\mathrm{pH}$ condition. The degraded drug products provide information in to the potential impurities of the drug that may be generated during stability testing. Forced degradation studies can also be used to quickly assess packaging material compatibility or sensitivity 
Forced degradation studies of bulk drug and synthetic formulations

In order to determine whether the developed analytical method was stability indicating, active pharmaceutical ingredient (API) and synthetic formulation of PRAMI and RASA were degraded under various stressed conditions to conduct forced degradation studies.

For API and synthetic formulations, stock solution of PRAMI and RASA (1:2.5) was prepared separately in Methanol (Preparation of std stock solution) These stock solutions were used for forced degradation studies to provide an indication of the stability indicating property and specificity of proposed method.

\section{Preparation of acid induced degradation product}

Accurately weighed $24 \mathrm{mg}$ and $60 \mathrm{mg}$ of PRAMI AND RASA respectively, were taken in $10 \mathrm{~mL}$ volumetric flask separately and dissolved in $4 \mathrm{~mL}$ of Methanol The volume was made up with 0.1N HCL and was kept at RT. Then $1 \mathrm{~mL}$ of above solution was withdrawn and was neutralized with $0.1 \mathrm{~N} \mathrm{NaOH}$. Then sample was diluted upto mark with diluent i.e. mobile phase and subjected to analysis.

Preparation of base induced degradation product

Accurately weighed $24 \mathrm{mg}$ and $60 \mathrm{mg}$ of PRAMI AND RASA respectively, were taken in $10 \mathrm{~mL}$ volumetric flask separately and dissolved in $4 \mathrm{~mL}$ of Methanol The volume was made up with $0.1 \mathrm{~N}$ $\mathrm{NaOH}$ and was kept at RT. Then $1 \mathrm{~mL}$ of above solution was withdrawn and was neutralized with 0.1N HCL. Then sample was diluted upto mark with diluent i.e. mobile phase and subjected to analysis (Figure 21,22).

\section{Photochemical degradation}

For the photochemical stability, the mixture of solid drugs (API) was spread in $1 \mathrm{~mm}$ thickness on a petridish and exposed to 5382 LUX and $144 \mathrm{UW} / \mathrm{cm}^{2}$ for 1 days. Degradation samples were subjected to analysis after suitable dilutions with Mobile phase (Figure 23).

\section{Dry heat induced degradation}

For preparing dry heat degradation product, API of PRAMI and RASA were placed in oven at $70^{\circ} \mathrm{C}$ for 1 days under dry heat condition in the dark and then cooled to room temperature. Degradation samples were subjected to analysis after suitable dilutions with Mobile phase (Figure 24,25).

Preparation of degradation sample of prepared laboratory mixture

The specifications for preparation of the laboratory synthetic mixture are mentioned in last section. $1 \mathrm{~mL}$ of prepared synthet- ic mixture was withdrawn accurately and transferred to a $10 \mathrm{~mL}$ volumetric flask containing suitable stressor. Aliquot of $1 \mathrm{~mL}$ was withdrawn accurately and neutralized if required, finally the volume being made upto $10 \mathrm{~mL}$ using Mobile phase. For Photochemical, Dry heat and Thermal-Humidity induced degradation, suitable amount of laboratory mixture was spread uniformly and subjected to stressor treatment as specified. Appropriate dilutions of the degradation samples were then subject to analysis (Table 15).

\section{Preliminary studies}

First of all, stressor concentration, stressor temperature and stressor time was optimized individually for both drugs to achieve an appropriate degradation. Then these conditions were optimized for both drugs together. Finally optimized stressor condition for both drugs together:

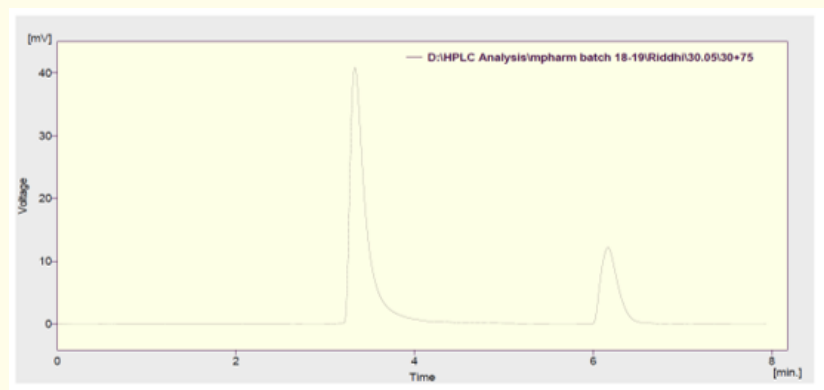

Figure 21: Control chromatogram. (PRAMI and RASA at RT mp and analysed. Results of Forced degradation studies.

\section{Results of Forced degradation studies}

Acid- induced degradation

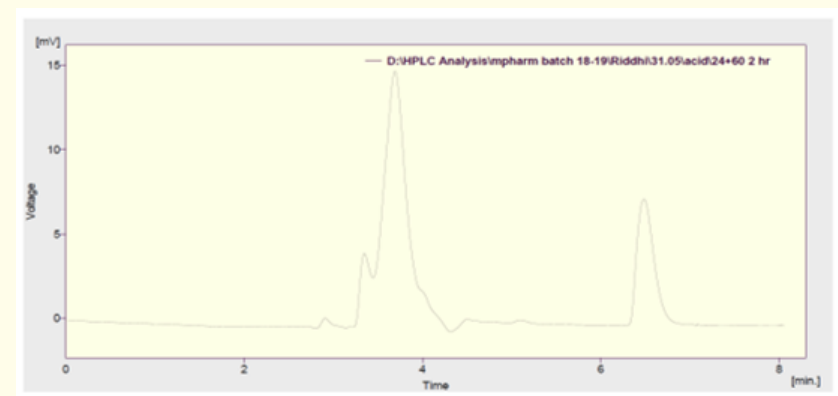

Figure 22: Acid degradation of mixture PRAMI and RASA (2hr) 
Development and Validation of Chemometric Assisted Methods and Stability Indicating RP-HPLC Method for Simultaneous Estimation of Rasagiline Mesylate and Pramipexole in Synthetic Mixture

Base induced degradation

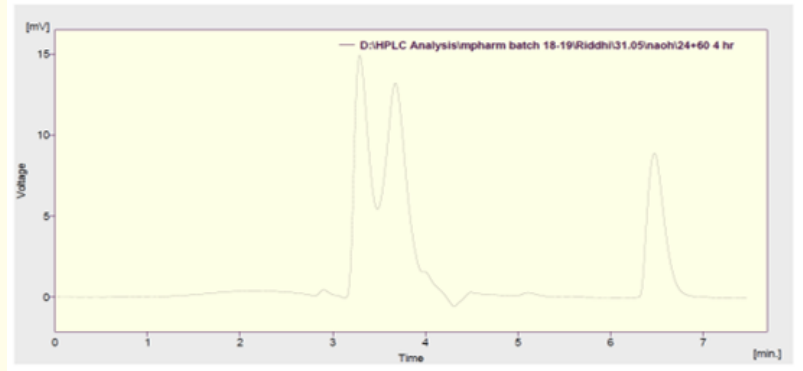

Figure 23: Base degradation of mixture PRAMI and RASA (2hr).

Dry Heat Induced Degradation

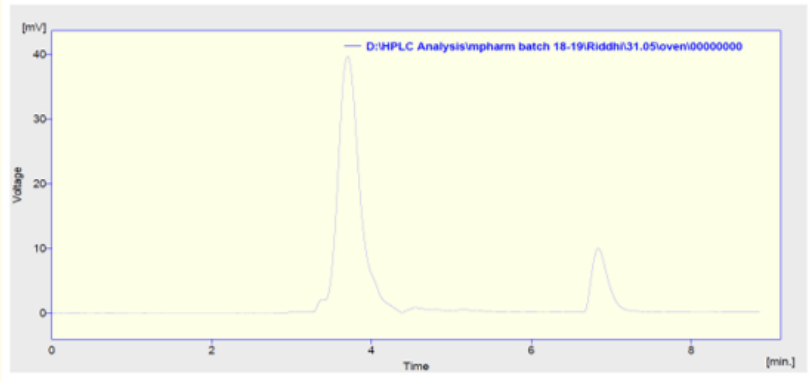

Figure 24: Dry heat studies at $70^{\circ} \mathrm{C}$ of PRAMI and RASA after 1 days.(intensity of the peaks remain consistent with all the time intervals).

Photochemical degradation

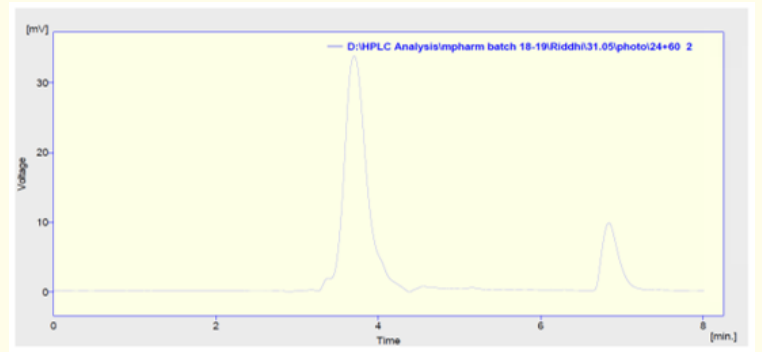

Figure 25: Dry heat studies at $70^{\circ} \mathrm{C}$ of PRAMI and RASA after 1 days. (intensity of the peaks remain consistent with all the time intervals).
Result and Discussion

\begin{tabular}{|l|c|c|}
\hline Analytical Prameter & \multicolumn{2}{|c|}{ First Derivative ZCP } \\
\hline Drugs & RASA & PRAMI \\
\hline$\lambda \mathbf{m a x}_{, \mathrm{nm}}$ & $272 \mathrm{~nm}$ & $262 \mathrm{~nm}$ \\
\hline LINEARITY & $15-90 \mu \mathrm{g} / \mathrm{ml}$ & $6-36 \mu \mathrm{g} / \mathrm{ml}$ \\
\hline Slope & -0.0003 & -0.0010 \\
\hline Intercept & 0.0025 & 0.0016 \\
\hline Correlation oefficient & 0.994 & 0.995 \\
\hline Standard Deviation of Intercept & 0.00036 & 0.00033 \\
\hline LOD & 3.976 & 1.117 \\
\hline LOQ & 12.05 & 3.385 \\
\hline
\end{tabular}

Table 3: Linearity study.

\begin{tabular}{|l|c|c|}
\hline Parameters & \multicolumn{2}{|c|}{ First Dvt. ZCP } \\
\hline & RASA & PRAMI \\
\hline Intraday \%RSD & 0.293 & 0.214 \\
\hline Interday RSD & 0.296 & 0.219 \\
\hline
\end{tabular}

Table 4: Precision Studies.

\begin{tabular}{|l|c|c|c|}
\hline \multirow{2}{*}{ Drug } & \multicolumn{3}{|c|}{ First Derivative ZCP method } \\
\hline \multirow{3}{*}{ RASA } & \%spiking & Base Conc. & \%recovery SD \\
\cline { 2 - 3 } & 80 & \multirow{2}{*}{$50 \mu \mathrm{g} / \mathrm{ml}$} & $99.44 \% \pm 0.18$ \\
\cline { 2 - 2 } & 100 & & $100.47 \pm 0.26$ \\
\cline { 2 - 2 } & 120 & & $101.9 \pm 0.19$ \\
\hline \multirow{3}{*}{ PRAMI } & 80 & & $101.28 \pm 0.75$ \\
\cline { 2 - 2 } & 100 & \multirow{2}{*}{$20 \mu \mathrm{g} / \mathrm{ml}$} & $101.22 \pm 0.76$ \\
\cline { 2 - 2 } & 120 & & $99.93 \pm 0.18$ \\
\hline
\end{tabular}

Table 5: Recovery Studies.

Applicability of proposed UV method

Result of Simultaneous estimation of RASA and PRAMI in synthetic mixture.

\begin{tabular}{|c|c|c|c|}
\hline \multirow{3}{*}{$\begin{array}{l}\text { Sr. No } \\
1\end{array}$} & \multicolumn{3}{|c|}{$\begin{array}{l}\text { Synthetic Mixture Label Claim: RASA: PRAMI } \\
0.75: 0.3 \mathrm{mg}\end{array}$} \\
\hline & Method & \multicolumn{2}{|c|}{ \% Assay } \\
\hline & \multirow[t]{2}{*}{$\mathrm{ZCP}$} & $\mathrm{RASA} \pm \mathrm{SD}$ & $\mathrm{PRAMI} \pm \mathrm{SD}$ \\
\hline & & $101.44 \pm 0.36$ & $99.25 \pm 0.33$ \\
\hline
\end{tabular}

Table 6: Assay of proposed UV Method. 


\begin{tabular}{|l|c|c|}
\hline \multirow{2}{*}{ Drug } & RMSEP & \\
\cline { 2 - 3 } & PCR & PLS \\
\hline RASA & 0.00954 & 0.00954 \\
\hline PRAMI & 0.00964 & 0.00954 \\
\hline
\end{tabular}

Table 7: RMSEP value.
Applicability of the developed chemometric methods

All four methods were successfully applied for the estimation of PRAMI and RASA in synthetic mixture.

\begin{tabular}{|l|c|c|}
\hline Method & RASA & PRAMI \\
\hline PCR & $99.764 \pm 0.298$ & $102.614 \pm 0.773$ \\
\hline PLS & $100.16 \pm 0.149$ & $101.503 \pm 0.572$ \\
\hline
\end{tabular}

Table 8: Applicability of Methods.

\begin{tabular}{|c|c|c|c|c|c|c|c|c|}
\hline \multirow[t]{2}{*}{ \% spiking } & \multicolumn{2}{|c|}{$\begin{array}{l}\text { Concentration } \\
\text { actual }(\mu \mathrm{g} / \mathrm{ml})\end{array}$} & \multicolumn{2}{|c|}{$\begin{array}{c}\text { Concentration added } \\
(\mu \mathrm{g} / \mathrm{ml})\end{array}$} & \multicolumn{2}{|c|}{$\begin{array}{c}\text { Concentration added } \\
(\mu \mathrm{g} / \mathrm{ml})\end{array}$} & \multicolumn{2}{|c|}{ \%Recovery \pm SD; $n=3$} \\
\hline & RASA & PRAMI & RASA & PRAMI & RASA & PRAMI & RASA & PRAMI \\
\hline 80 & 100 & 40 & 80 & 32 & 80.5 & 31.6 & $100.65 \pm 0.842$ & $98.84 \pm 0.953$ \\
\hline 100 & & & 100 & 40 & 100.5 & 39.8 & $101.58 \pm 1.262$ & $99.73 \pm 0.639$ \\
\hline 120 & & & 120 & 48 & 119.8 & 47.6 & $99.85 \pm 1.30$ & $99.33 \pm 0.507$ \\
\hline
\end{tabular}

Table 9: Accuracy results of RASA and PRAMI (HPLC).

\begin{tabular}{|c|c|c|c|c|c|c|c|c|c|}
\hline \multicolumn{2}{|c|}{$\begin{array}{l}\text { CONC. }(\mu \mathrm{g} / \\
\mathrm{ml})\end{array}$} & \multicolumn{4}{|c|}{ Intraday precision } & \multicolumn{4}{|c|}{ Interday precision } \\
\hline \multirow[b]{2}{*}{ RASA } & \multicolumn{2}{|c|}{ MEAN AREA \pm SD; $n=3$} & \multicolumn{2}{|l|}{ \%RSD } & \multicolumn{2}{|c|}{ MEAN AREA \pm SD; $n=3$} & \multicolumn{2}{|l|}{ \%RSD } & \multirow[b]{2}{*}{$\begin{array}{c}\text { PRA- } \\
\text { MI }\end{array}$} \\
\hline & $\begin{array}{l}\text { PRA- } \\
\text { MI }\end{array}$ & RASA & PRAMI & RASA & $\begin{array}{l}\text { PRA- } \\
\text { MI }\end{array}$ & RASA & PRAMI & RASA & \\
\hline 40 & 20 & $589103 \pm 7409.1$ & $96427.3 \pm 982.857$ & 0.693 & 1.737 & $592735 \pm 4348.58$ & $96585.7 \pm 934.183$ & 0.733 & 1.096 \\
\hline 100 & 40 & $763995 \pm 7814.56$ & $118837 \pm 1125.39$ & 0.804 & 0.947 & $756101 \pm 6174.41$ & $116390 \pm 1233.54$ & 0.816 & 1.059 \\
\hline 150 & 60 & $923118 \pm 10782.8$ & $134413 \pm 1554.18$ & 1.168 & 1.152 & $9166487 \pm 6315.51$ & $134346 \pm 1369.93$ & 0.689 & 1.017 \\
\hline
\end{tabular}

Table 10: Precision results in HPLC.

\begin{tabular}{|l|c|c|}
\hline PARAMETER & RASA & PRAMI \\
\hline $\mathrm{LOD}(\mu \mathrm{g} / \mathrm{ml})$ & 0.0583 & 0.1768 \\
\hline $\mathrm{LOQ}(\mu \mathrm{g} / \mathrm{ml})$ & 0.1036 & 0.3141 \\
\hline
\end{tabular}

Table 11: LOD and LOQ HPLC.

\begin{tabular}{|l|c|c|}
\hline \multirow{2}{*}{ Parameter } & \multicolumn{2}{|c|}{ Data obtained } \\
\cline { 2 - 3 } & RASA & PRAMI \\
\hline RETENTION TIME \pm SD & $6.124 \pm 0.073$ & $3.325 \pm 0.053$ \\
\hline Theoretical plate \pm SD & $2339 \pm 132.672$ & $4898 \pm 141.623$ \\
\hline Tailing factor \pm SD & $1.968 \pm 0.020$ & $1.2 \pm 0.031$ \\
\hline Resolution \pm SD & $6.538 \pm 0.259$ & $12.695 \pm 0.147$ \\
\hline
\end{tabular}

Table 12: System Suitability results.
Summary of validation results for the developed method

\begin{tabular}{|l|c|c|}
\hline Parameter & RASA & PRAMI \\
\hline $\begin{array}{l}\text { Analytical Wavelength } \\
(\mathrm{Nm})\end{array}$ & \multicolumn{2}{|c|}{$265 \mathrm{~nm}$} \\
\hline Retention Time (Min) & $6.1 \mathrm{~min}$ & $3.3 \mathrm{~min}$ \\
\hline Linearity (Mg/Ml) & $15-90 \mu \mathrm{g} / \mathrm{ml}$ & $6-36 \mu \mathrm{g} / \mathrm{ml}$ \\
\hline Regression Equation & $\mathrm{y}=608 \mathrm{x}+76340$ & $\mathrm{y}=8910 \mathrm{x}+37081$ \\
\hline $\begin{array}{l}\text { Interday Precision } \\
\text { (\%Rsd) }\end{array}$ & 1.057 & 0.746 \\
\hline $\begin{array}{l}\text { Intraday Precision } \\
\text { (\%Rsd) }\end{array}$ & 1.278 & 0.888 \\
\hline LOD & 0.176 & 0.058 \\
\hline LOQ & 0.314 & 0.103 \\
\hline Accuracy (\%Recovery) & 102.32 & 98.612 \\
\hline
\end{tabular}

Table 13: Summary of Validation parameters. 
Development and Validation of Chemometric Assisted Methods and Stability Indicating RP-HPLC Method for Simultaneous Estimation of Rasagiline Mesylate and Pramipexole in Synthetic Mixture

\begin{tabular}{|l|c|c|c|c|}
\hline Sample & Label claim & Avg Amount found & \%Assay (Avg \pm SD); n=6 & \%RSD \\
\hline RASA & $0.75 \mathrm{mg}(10 \mathrm{mg})$ & $9.970 \mathrm{mg}$ & $99.70 \pm 412$ & 0.422 \\
\hline PRAMI & $0.3 \mathrm{mg}(4 \mathrm{mg})$ & $3.95 \mathrm{mg}$ & $98.751 \pm 0.364$ & 0.377 \\
\hline
\end{tabular}

Table 14: Assay results HPLC.

\begin{tabular}{|l|c|c|c|}
\hline Stressor condition & Stressor concentration & Stressor temperature & Stressor time \\
\hline Acidic & $0.1 \mathrm{~N} \mathrm{HCl}$ & $\mathrm{RT}$ & $2 \mathrm{hrs}$ \\
\hline Basic & $0.1 \mathrm{~N} \mathrm{NaOH}$ & $\mathrm{RT}$ & $2 \mathrm{hrs}$ \\
\hline Photostability & $5382 \mathrm{LUX}$ and $144 \mathrm{UW} / \mathrm{cm}^{2}$ & -- & 1 days \\
\hline Dry heat stability & - & $70^{\circ} \mathrm{C}$ & 1 days \\
\hline
\end{tabular}

Table 15: Degradation Study Parameters.

Summary of Forced Degradation Studies

\begin{tabular}{|l|l|l|l|l|l|l|}
\hline $\begin{array}{l}\text { Stresso } \\
\text { R Type }\end{array}$ & $\begin{array}{l}\text { Stressor } \\
\text { Concentration }\end{array}$ & Stresso R Time & \multicolumn{2}{l|}{$\begin{array}{l}\text { \% Degradation } \\
\text { (Api) }\end{array}$} & \multicolumn{2}{l}{$\begin{array}{l}\text { \% Degradation } \\
\text { (Synthetic Formulation) }\end{array}$} \\
\hline & & & RASA & PRAMI & RASA & PRAMI \\
\hline ACIDIC & $0.1 \mathrm{~N}$ HCL at RT & $2 \mathrm{hrs}$ & $39.5 \%$ & $23.7 \%$ & $40.2 \%$ & $23.3 \%$ \\
\hline BASIC & $0.1 \mathrm{~N}$ NaOH at RT & $2 \mathrm{hrs}$ & $41.34 \%$ & $3.8 \%$ & $41.2 \%$ & $3.4 \%$ \\
\hline
\end{tabular}

Table 16: Summary Of Forced Degradation Studies.

\section{Conclusion}

Application of Chemometric to UV Spectrophotometry is an effective tool for simultaneous estimation of Rasagiline Mesylate and Pramipexole which offers striking advantage in terms of time required for analysis, simplicity, accuracy and precision. Developed RP-HPLC method found to be stability indicating all the models are found to be applicable for analysis of synthetic mixture. The methods were validated and satisfactory results were produced. PCR and PLS methods were also validated using full cross validation model.

\section{Bibliography}

1. Warren Olanow MD., et al. "A Randomized Trial of a Low- Dose Rasagiline and Pramipexole Combination (P2B001) in Early Parkinson's Disease C". Movement Disorders 32.5 (2017): 783789.

2. Patel Pinal R. "Development and Validation of a Spectrophotometric method for estimation of Rasagiline Mesylate in bulk and tablet dosage Form". International Journal of Drug Development and Research (2013).
3. Rama Bukka and Kalyani Prakasam. "Uv Spectrophotometric Method For The Determination Of Rasageline Mesylate In Bulk And Pharmaceutical Formulations". International Journal of Pharmaceutical Sciences Review and Research 5.1 (2010): 5-7.

4. Vijaya Lakshmi1 JVLN., et al. "Development and Validation Of Rp-Hplc Method For The Estimation Of Rasagiline Tablet Dosage Forms". Journal of Chemistry 3.4 (2010): 621-624.

5. PG Shelke and AV Chandewar P. "Validated high performance liquid chromatographic method for determination of Rasagiline Mesylate under oxidative, photolytic and thermal stress Conditions". IndiaInternational Journal of PharmTech Research 6.2 (2014).

6. Ramadevi Uppara R., et al. "Analytical Method Development and Validation of Pramipexole In Bulk and Formulations By Using Uv Spectroscopic Technique". European Journal of Pharmaceutical and Medical Research (2017).

7. By P Lavudu., et al. "Rp-Hplc Method for the Determination of Pramipexole Dihydrochloride in Tablet Dosage Form". Global Journal of Medical research 12.4 (2012). 
8. vilas Chaudhary1 and Milind Ubale. "Development and Validation Of Rp-Hplc Method For Estimation Of Pramipexole Hydrochloride In Pharmaceutical Dosage Form". International Journal of Research In Pharmacy And Chemistry 3.1 (2013).

9. Shubhangi M., et al. "Establishment of inherent stability of pramipexole and development of validated stability indicating LC-UV and LC-MS method". Journal of Pharmaceutical Analysis 3.2 (2013):109-117.

10. Beckett AH and Stenlake JB. "UV-visible Spectrophotometry". Practical Pharmaceutical Chemistry, 4th ed., Part-II, C.B.S. Publishers, Delhi (2001): 285-297.

11. ICH Q2 (R1). "Validation of analytical procedure Text and methodology". Geneva, International conference on Harmonization (2005).

12. Prachi Bhamre., et al. "Simultaneous determination of Doxylamine succinate, Pyridoxine hydrochloride and folic acid by Chemometric spectrophotometry". International Journal of Pharma and Bio Sciences 4.1 (2013): 738 - 749.

13. Garcia H and Filzmoser P. "Multivariate Statistical Analysis using the R package Chemometrics". (2011).

14. James N Miller and Jane C Miller. "Statistics and Chemometrics for Analytical Chemistry". 5th edition, Pearson Education Limited Edinburgh Gate, Harlow Essex (2005).

15. Richard Kramer. "Applied Chemometrics Inc. Chemometric technique for quantitative analysis, Marcel Dekker Inc. New York (1998).

Volume 3 Issue 8 August 2019

(C) All rights are reserved by Riddhi Patel and Rajashree

Mashru.

Citation: Riddhi Patel and Rajashree Mashru. "Development and Validation of Chemometric Assisted Methods and Stability Indicating RP-HPLC Method for Simultaneous Estimation of Rasagiline Mesylate and Pramipexole in Synthetic Mixture”. Acta Scientific Pharmaceutical Sciences 3.8 (2019): $154-168$. 